\title{
Quality of life and impact of bile reflux after retro colic retro gastric gastrojejunostomy in Whipple surgery
}

\author{
Rohan Chaminda Siriwardana1*, Rajapaksha Walimuni Mudiyanselage Anuradha Lokubandara', \\ Shivanthi Janaki De Silva Hewavisenthi ${ }^{2}$, Saumya Kumuduni Liyanage ${ }^{2}$, Dona Subani Priyangika Jayatunge ${ }^{1}$ \\ and Chandika Anuradha Habarakada Liyanage ${ }^{1}$
}

\begin{abstract}
Background: Delayed gastric emptying and bile reflux are common concerns in long-term survivors after Whipple surgery. The study was designed to assess modified retro colic retro gastric gastrojejunostomy in reducing macro and microscopic bile reflux and impact on dyspepsia related quality of life in long-term survivors.

Methods: Out of 43 patients operated, 23 long-term survivors were included. All underwent gastroscopy and bile reflux was grouped as normal, yellowish bile lakes and presence of greenish bile lakes. Six standard gastric biopsies were taken. Microscopic bile reflux index (BRI) was calculated and a score more than 14 was considered significant. Validated Nepean dyspepsia index-short form (NDI-SF) was used to assess the severity of dyspepsia-related quality of life and compared with age and gender-matched control.

Results: The median age was 48 (21-70) years. Median survival of the group was 37 months (6-40). Endoscopically, 20/23 (87\%) had macroscopic bile reflux (74\% yellowish bile lakes, 13\% greenish bile lakes). None had stomal ulcers or macroscopic inflammation. Mean bile reflux index score was 9.7 (range 1.77-34). Mean NDI-SF score of Whipple group was 23.1 (SD 8.88). In controls, mean score was 19.9 (SD 8.23), showing no significant difference ( $p=0.245$ ).
\end{abstract}

Conclusions: Though there was macroscopic bile reflux, clinical symptoms and microscopic changes were minimal. The modified technique had good long-term results.

Keywords: Whipple surgery, Bile reflux, Quality of life

\section{Background}

Whipple surgery was once a procedure associated with high morbidity and mortality rates. However over the years, perioperative outcome has improved. Currently it is a safe surgery with low morbidity and mortality $[1,2]$. Now the focus has shifted from improving perioperative outcome to improving long-term survival and quality of life $[3,4]$. Delayed gastric emptying and bile reflux gastritis are the main concerns of long-term survivors [3]. Many surgical techniques are being used by different centers to overcome this. Pylorus preservation, the use of separate loop to drain bile and use of retro colic loop are some of

\footnotetext{
* Correspondence: rohansiriwardana@yahoo.com

${ }^{1}$ Department of Surgery, Faculty of Medicine, University of Kelaniya, Ragama, Sri Lanka

Full list of author information is available at the end of the article
}

the adaptations used [5-7]. Khan et.al described a novel technique in performing the gastrojejunostomy and reported superior early results with the technique [8]. During this reconstruction, posterior gastrojejunostomy is pulled in to the infra colic compartment and anchored to the transverse mesocolon. This helps the anastomosis to retain in a dependent anatomical position. However longterm outcome is not reported. This study looks at intermediate results of patients who underwent retro colic retro gastric gastrojejunostomy with a mesocolic stich.

\section{Methods}

Forty three patients who underwent Whipple surgery from January 2012 for malignant disease were included in the study. Patients with recurrence of primary malignancy, those who had immediate post-operative 
complications that needed relaporotomy, those who underwent chemotherapy within the last 6 months, and those who did not consent were excluded from the study. There were 23 patients who fulfilled the inclusion criteria (Fig. 1). There were no pancreatic leaks in the group. All surgeries were done by two hepatobiliary surgeons who worked in parallel. A standard technique was used for Whipple surgery in all cases. The common bile duct was divided at the level of the cystic duct. All the nodes to the right of the common hepatic artery were taken as specimen. Pancreatic division was done at the level of the neck. The uncinate process was completely removed clearing all the tissues to the right of the superior mesenteric artery. The stomach was divided at the level of the incisura. After the dissection, reconstruction was done using a single Roux loop taken through a window in the transverse mesocolon. The pancreas was anastomosed using 'end to side two layer' technique. This was followed by 'end to side biliary reconstruction'. A $60 \mathrm{~cm}$ gap was left between hepaticojejunostomy and gastrojejunostomy. A separate mesenteric window was made in the left edge of the transverse mesocolon and the small bowel was taken to the supracolic compartment through this window. A two layer longitudinal $4 \mathrm{~cm}$ hand-sewn gastrojejunostomy was made in the posterior surface of the stomach close to the distal end of the gastric stump. The anastomosed distal stomach was then pulled down in to the infracolic compartment. The gastric stump was anchored to the mesenteric window to prevent retraction. All 23 patients were being followed up at the hepatobiliary clinic at regular intervals.

The patients were evaluated at 6 months after the surgery. The patients who fulfilled the inclusion criteria underwent upper gastric endoscopy. Two observers documented the macroscopic appearance of the gastric mucosa. Sample color photographs were used as a guide to categorize the macroscopic appearance. Macroscopic appearance was categorized as normal, presence of yellowish bile lakes, presence of greenish bile lakes, presence of gastric inflammation and presence of stromal ulcers. Six biopsies were taken from six standard sites to represent the stomach. Biopsy specimens were stained with Hematoxylin and Eosin. Giemsa stain was done to detect Helicobacter pylori. Two pathologists evaluated all specimens separately. Discrepancies in scores were resolved through discussion until both pathologists agreed on common scores. Bile reflux was reported using a previously published bile reflux index (BRI). The index was calculated using the formula: $7 \mathrm{x}$ oedema of lamina propria $+3 \mathrm{x}$ intestinal metaplasia $+4 \mathrm{x}$ chronic

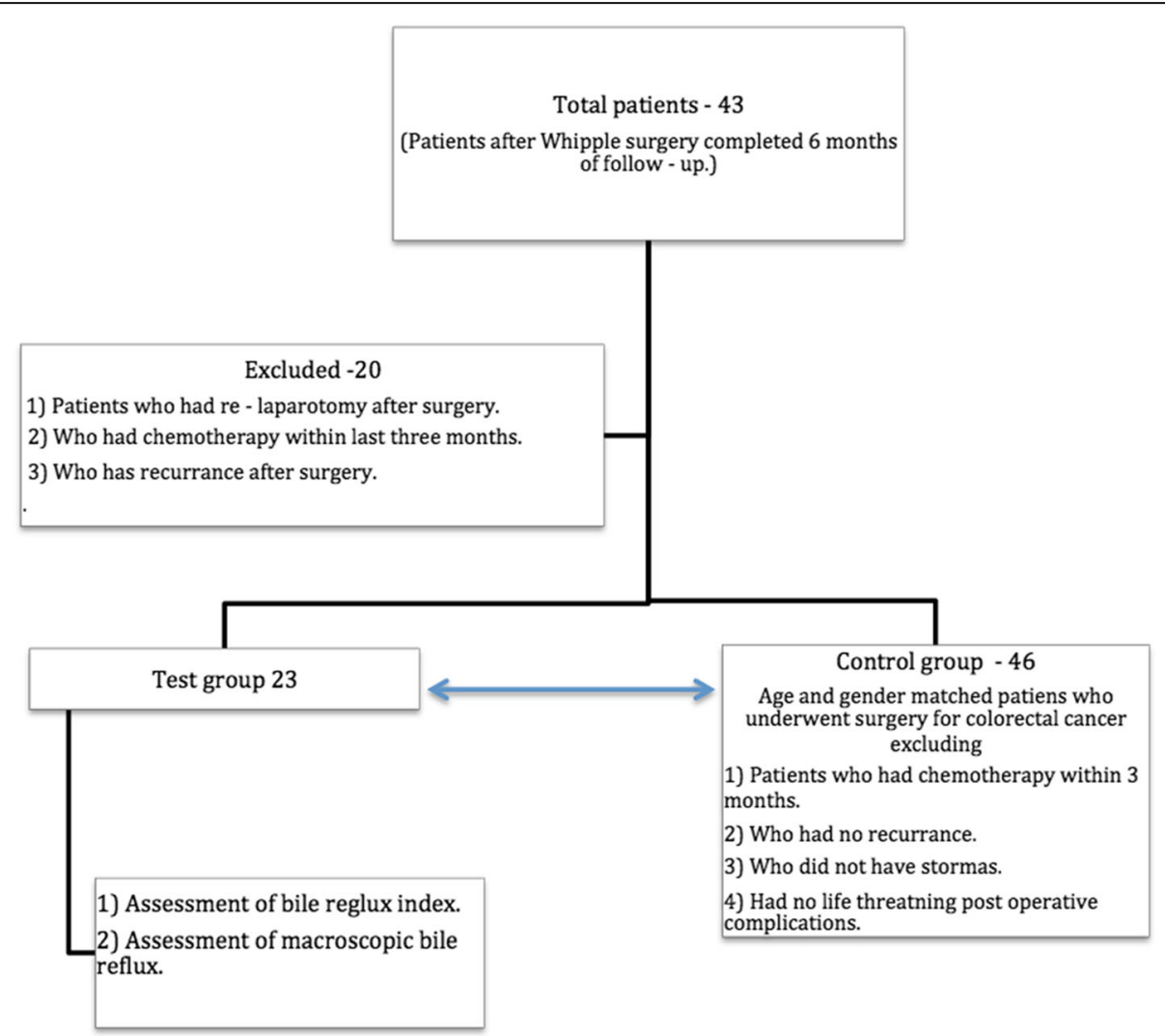

Fig. 1 Selection of patients and controls 
inflammation-6 x H.pylori. An index over 14 was considered significant.

Patient's quality of life was assessed using Nepean dyspepsia short form quality of life (NDI-SF) questionnaire [9]. The questionnaire was translated to native language and was validated before using. Each patient was matched with two controls according to the age and gender. Controls were selected from a cohort of patients who had undergone lower abdominal surgeries for colorectal cancer. Patients who had recurrent disease, patients who had stomas, patients with bowel related complications or patients who were on chemotherapy within last 3 months were excluded. The NDI-SF score was compared between the two groups.

The study was approved by the Ethical Review Committee of the Faculty of Medicine, University of Kelaniya. All data were analyzed using SPSS 20. A $p$ value of less than 0.05 was considered significant.

\section{Results}

The median survival of the group was $37(6-40)$ months. $10(45 \%)$ were males. The median age was $48(21-70)$ years. Median body mass index was $20.32 \mathrm{~kg} / \mathrm{m}^{2}$ (15.03-30.07). 16 (69\%) of them had diabetes. There were $10(43 \%)$ patients with pancreatic cancers, 2 (8.6\%) with bile duct cancers, 2 (8.6\%) with neuroendocrine tumours, and 9 (40\%) with periampullary cancers. None of the patients in the group had early delayed gastric emptying. 6 (26\%) Patients had adjuvant chemotherapy.

During endoscopy, 17 (74\%) had yellowish bile lakes and $3(13 \%)$ had greenish bile lakes. None of them had macroscopic gastric inflammation or stromal ulcers. In the microscopic assessment, the median BRI in the group was 9.7 (range 1.77-34). Only 5 patients had BRI over 14. Helicobacor pylori was not positive in any of the biopsies taken.
The quality of life was assessed in 10 areas. The overall score in the control was 19.9 (SD 8.23) while it was 23.1 (SD 8.88) in the test group indicating no significant difference $(p=0.245)$. The scores were comparable in the individual areas of NDI-SF (Table 1).

\section{Discussion}

In this cohort who had intermediate survival after Whipple surgery, bile was commonly noted in the distal part of the gastric stump. However biopsies did not show significant microscopic changes of bile reflux. Their quality of life was also comparable to the control. Maintaining the gastric stump in near-anatomical position, preventing stump retraction and angulation are considered important causes for good functional results after gastrectomy [6]. In the technique we use, the stomach is anchored to the root of the mesentery that helps to maintain its position. Furthermore there may be a mechanical advantage of keeping the gastric anastomosis in the infracolic compartment that facilitate the rapid emptying of the bile that enters in to the stomach.

Bile reflux gastritis is a well known histological entity characterized by foveolar hyperplacia, mucosal oedema, congestion and presence of acute and chronic inflammation [10]. Persistent bile reflux into the gastric remnant is known to cause significant clinical symptoms, structural changes and gastric carcinoma [10, 11]. However data looking specifically at bile reflux after Whipple surgery is limited in literature. Most data are from studies that used gastrectomy for distal gastric or duodenal cancer. In these studies, Roux en Y reconstruction was used to overcome bile reflux after distal gastrectomy $[12,13]$. However, mobilizing a separate limb for biliary diversion adds more surgical time in addition to inherent problems of the Roux loop [14]. Another technique used is Braun enterostomy which has shown to reduce the incidence of bile reflux and delayed gastric emptying [15]. Additional jejunojejunostomy prolongs the surgical time

Table 1 Nepean dyspepsia index in the test and the control groups

\begin{tabular}{|c|c|c|c|}
\hline & Study group mean (SD) & Control group mean (SD) & $P$ value \\
\hline General emotional well-being been disturbed by stomach problems & $2.10(1.07)$ & $2.45(1.39)$ & 0.615 \\
\hline Irritable, tense or frustrated because of stomach problems & $2.30(1.13)$ & $1.95(1.10)$ & 0.530 \\
\hline Ability to engage in things usually do for fun been disturbed by stomach problems & $2.55(1.47)$ & $2.05(1.32)$ & 0.772 \\
\hline Enjoyment of things done usually for fun been disturbed by stomach problems & $2.10(1.33)$ & $2.75(1.48)$ & 0.396 \\
\hline Ability to eat or drink been disturbed by stomach problems & $2.15(1.50)$ & $2.10(1.25)$ & 0.726 \\
\hline Enjoyment of eating and/or drinking been disturbed by stomach problems & $2.10(1.25)$ & $2.15(1.18)$ & 0.687 \\
\hline Feeling that they will always have stomach problems & $2.45(1.43)$ & $2.00(0.92)$ & 0.353 \\
\hline Feeling of stomach problems might be due to a very serious illness. & $2.05(1.43)$ & $1.75(1.07)$ & 0.289 \\
\hline Ability to work or study been disturbed by stomach problems & $2.50(1.70)$ & $1.40(1.23)$ & 0.222 \\
\hline Enjoyment of work or study been disturbed by stomach problems & $2.50(1.70)$ & $1.40(1.14)$ & 0.132 \\
\hline Total score & $23.10(8.88)$ & $19.90(8.23)$ & 0.245 \\
\hline
\end{tabular}


and can lead to other anastomosis related complications. In comparison to both these techniques, single loop reconstruction that we used is simple and is easy to perform.

Macroscopic bile reflux was noted in $87 \%$ of our cases. Bile pooled mainly in the distal stomach. Previous data from Fukuhara et.al [15] and others [16, 17] had shown a significant relationship between mucosal inflammation and presence of Helicobacter pylori infection. None of our patients had Helicobacter pylori present in the gastric mucosa. This could be an additional factor for not having significant mucosal inflammation. The median time for our evaluation since the surgery was 37 months. In a previous study, patients presenting with symptoms after gastrostomy showed bile reflux gastritis (BRG) in $60 \%$ of the cases after 14 years of surgery [18]. However other studies have shown mucosal changes much earlier [19]. Therefore median follow-up of 37 months in our cohort seems to be adequate to develop mucosal changes.

Delayed gastric emptying (DGE) is a well known complication after Whipple surgery. Incidence of early DGE is recorded to be around $20-30 \%$. Its long-term impact and incidence of persistent symptoms is rarely discussed. Delayed gastric emptying is reported in around $10-20 \%$ of patients at 3 years after Whipple surgery [20]. In another study using standard reconstruction showed a similar incidence of DGE assessed with $\mathrm{C} 13$ acetate breath test at 24 months after surgery [21]. However gastric emptying studies need to be interpreted carefully in these patients who had lost a significant part of the stomach. In our study, gastric emptying time was not assessed. We feel that results of emptying studies have a little value in the absence of significant mucosal changes and symptoms.

One of the main drawbacks in the study is that it evaluates a smaller cohort of patients. Since this is the standard technique used in the center for reconstruction, we were not able to compare with a cohort reconstructed with an alternate technique. Since bile reflux index is a standard method in assessing bile reflux, we feel that having a lower BRI score without comparison is acceptable in arriving at our conclusion. However quality of life is best compared with a cohort having alternative reconstruction technique. To overcome this we selected a group of patients who had colonic surgeries unlikely to have upper gastric symptoms.

\section{Conclutions}

Patients with retro colic retro gastric gastrojejunostomy have good quality of life and minimal gastric mucosal changes. The technique seems to give good long-term results after Whipple surgery. This technique needs to be evaluated in a larger cohort.

\section{Acknowledgements}

We thank Mrs. Pathirana P. M. P. L Staff Technical Officer for performing laboratory analyses.

We thank Dr. Bandara L. M. P. M who assisted in statistical analysis and data collection of the study.

We thank Miss Vishaka Lakchani who assisted in statistical analysis and data collection of the study.

\section{Funding}

Self funded.

\section{Availability of data and material}

The datasets used and/or analysed during the current study are available from the corresponding author on reasonable request.

\section{Authors' contributions}

RCS is the corresponding author. He has coordinated the works done from the beginning to the end. Whipple surgery was performed under his supervision. Data collection, analysis and document works were organized by him. RWMAL assisted the surgeries. And he also contributed in the data collection. SJDSH has coordinated pathological analysis and pathological data collection data collections. SKL has contributed in pathological analysis and pathological data collections. DSPJ is the research assistant who was responsible in collecting and entering the data. She also analysed the data and helped in the process of writing the research works. CAH performed the surgeries and he has given his support in organizing the research to the primary researcher. All the authors have read understood and approved the manuscript and its contents.

\section{Competing interests}

There are no competing interest in our research.

\section{Consent for publication}

All the participants were given prior knowledge about publishing the results after the end of the research.

\section{Ethics approval and consent to participate}

Ethical approval for the study for this research was given by the ethical review committee, Faculty of Medicine, University of Kelaniya.

For the participants details of the research purpose was explained by the research assistants and the informed written consent was taken. All the participants were given full freedom to leave the research at any point of time.

\section{Author details}

'Department of Surgery, Faculty of Medicine, University of Kelaniya, Ragama, Sri Lanka. ${ }^{2}$ Department of Pathology, Faculty of Medicine, University of Kelaniya, Ragama, Sri Lanka.

Received: 28 September 2016 Accepted: 11 January 2017

Published online: 21 January 2017

\section{References}

1. Grace PA, Pitt HA, Tompkins RK, Denbesten L, Longmire WP. Decreased morbidity and mortality after pancreatoduodenectomy. Am J Surg. 1986;151:141-9.

2. Trede M, Schwall G, Saeger HD. Survival after pancreatoduodenectomy. 118 consecutive resections without an operative mortality. Ann Surg. 1990:211:447-58.

3. Fitzmaurice C, Seiler CM, Büchler MW. Survival, mortality and quality of life after pylorus-preserving or classical Whipple operation. A systematic review with meta-analysis. Chirurg. 2010;81:454-71.

4. Ohtsuka T, Yamaguchi K, Ohuchida J, Inoue K, Nagai E, Chijiwa K, et al. Comparison of quality of life after pylorus-preserving pancreatoduodenectomy and Whipple resection. Hepatogastroenterology. 2003:50:846-50.

5. Eshuis WJ, Van Dalen JW, Busch ORC, van Gulik TM, Gouma DJ. Route of gastroenteric reconstruction in pancreatoduodenectomy and delayed gastric emptying. HPB. 2012;14:54-9.

6. Gangavatiker R, Pal S, Javed A, Dash NR, Sahni P, Chattopadhyay TK. Effect of antecolic or retrocolic reconstruction of the gastro/duodenojejunostomy 
on delayed gastric emptying after pancreaticoduodenectomy: a randomized controlled trial. J Gastrointest Surg. 2011;15:843-52.

7. Sobala GM, O'Connor HJ, Dewar EP, King RF, Axon AT, Dixon MF. Bile reflux and intestinal metaplasia in gastric mucosa. J Clin Pathol. 1993:46:235-40.

8. Khan AS, Hawkins WG, Linehan DC, Strasberg SM. A technique of gastrojejunostomy to reduce delayed gastric emptying after pancreatoduodenectomy. J Gastrointest Surg. 2011;15(8):1468-71.

9. Talley NJ, Haque M, Wyeth JW, Stace NH, Tytgat GN, Stanghellini V, et al. Development of a new dyspepsia impact scale: The Nepean Dyspepsia Index. Aliment Pharmacol Ther. 1999;13:225-35.

10. Dixon MF, O'Connor HJ, Axon AT, King RF, Johnston D. Reflux gastritis: distinct histopathological entity? J Clin Pathol. 1986;39:524-30.

11. Ritchie WP. Alkaline reflux gastritis. Can J Surg. 1982;25:248-9.

12. Osugi H, Fukuhara K, Takada N, Takemura M, Kinoshita H. Reconstructive procedure after distal gastrectomy to prevent remnant gastritis. Hepatogastroenterology. 2004;51:1215-8.

13. Cabrol J, Navarro X, Sancho J, Simo-Deu J, Segura R. Bile reflux in postoperative alkaline reflux gastritis. Ann Surg. 1990;211:239-43.

14. Hoya Y, Mitsumori N, Yanaga K. The advantages and disadvantages of a Roux-en-Y reconstruction after a distal gastrectomy for gastric cancer. Surg Today. 2009;39(8):647-51.

15. Watanabe $\mathrm{Y}$, Ohtsuka T, Kimura H, Matsunaga T, Tamura K, Ideno N, et al. Braun enteroenterostomy reduces delayed gastric emptying after pylorus-preserving pancreatoduodenectomy: A retrospective review. Am J Surg. 2015;209:369-77.

16. Fukuhara K, Osugi H, Takada N, Takemura M, Lee S, Taguchi S, et al: Correlation between duodenogastric reflux and remnant gastritis after distal gastrectomy. Hepatogastroenterology. 2004:51:1241-4.

17. Fukuhara K, Osugi H, Takada N, Takemura M, Lee S, Taguchi S, et al. Duodenogastric reflux eradicates Helicobacter pylori after distal gastrectomy. Hepatogastroenterology. 2004;51:1548-50

18. Vere CC, Cazacu S, Comănescu V, Mogoantă L, Rogoveanu I, Ciurea T. Endoscopical and histological features in bile reflux gastritis. Rom J Morphol Embryol. 2005;46:269-74.

19. Li XB, Lu H, Chen HM, Chen XY, Ge ZZ. Role of bile reflux and Helicobacter pylori infection on inflammation of gastric remnant after distal gastrectomy. J Dig Dis. 2008;9:208-12.

20. Matsumoto I, Shinzeki M, Asari S, Goto T, Shirakawa S, Ajiki T, et al. A prospective randomized comparison between pylorus- and subtotal stomach-preserving pancreatoduodenectomy on postoperative delayed gastric emptying occurrence and long-term nutritional status. J Surg Oncol. 2014;109(7):690-6.

21. Kawai M, Tani M, Hirono S, Okada K, Miyazawa M, Yamaue H. Pylorus-resecting pancreaticoduodenectomy offers long-term outcomes similar to those of pylorus-preserving pancreaticoduodenectomy: Results of a prospective Study. World J Surg. 2014;38:1476-83.

\section{Submit your next manuscript to BioMed Central and we will help you at every step:}

- We accept pre-submission inquiries

- Our selector tool helps you to find the most relevant journal

- We provide round the clock customer support

- Convenient online submission

- Thorough peer review

- Inclusion in PubMed and all major indexing services

- Maximum visibility for your research

Submit your manuscript at www.biomedcentral.com/submit

) Biomed Central 